
melão 'Amarelo' minimamente processado. Horticultura Brasileira 26:458-463.

\title{
Efeito de tratamentos químicos na respiração e parâmetros físicos de melão ‘Amarelo' minimamente processado
}

\author{
Ana Carolina A Miguel²; Gabriela F Begiato ${ }^{1}$; João Ricardo P Stein Dias'; ${ }^{1}$ Silvana Albertini ${ }^{1}$; Marta Helena F Spoto ${ }^{1}$ \\ ${ }^{1}$ USP-ESALQ, C. Postal 9, 13418-900 Piracicaba-SP; ${ }^{2}$ Bolsista CNPq; acmiguel@esalq.usp.br
}

\begin{abstract}
RESUMO
Neste trabalho avaliou-se o efeito da aplicação de tratamentos químicos na atividade respiratória e no impacto sobre os parâmetros físicos de melões 'Amarelo' minimamente processados. Frutos selecionados, lavados e sanificados foram minimamente processados em forma de cubos, divididos em quatro lotes que constaram de testemunha, cubos tratados com soluções de cloreto de cálcio (1\%), ácido ascórbico (1\%) e revestidos com alginato de sódio (1\%); os quais foram acondicionados em bandejas com tampa, de tereftalato de polietileno (PET) e armazenados a $5 \pm 1^{\circ} \mathrm{C}$ e $73 \pm 5 \%$ UR, por 12 dias. Os produtos foram avaliados quanto à taxa respiratória, produção de etileno, perda de massa fresca, coloração, textura e teor de umidade. Verificou-se que, durante o período de armazenamento, independente do tratamento, houve redução da respiração e não se detectou produção de etileno pelos frutos. A perda de massa, a textura e o teor de umidade não foram influenciados pelos tratamentos químicos, porém o uso de película à base de alginato de sódio resultou em melões de coloração mais escura da polpa, em decorrência da cor da solução filmogênica.
\end{abstract}

Palavras-chave: Cucumis melo L., processamento mínimo, respiração, parâmetros físicos.

\begin{abstract}
Effect of chemical treatments on respiratory process and physical parameters of melon minimally processed

The effect of the application of chemical treatments was evaluated on the respiratory activity and the impact on the physical parameters of fresh cut melons. Selected fruits were washed and sanitized and minimally processed in cubes, divided in four lots which consisted of: control, treated with calcium chloride (1\%), with ascorbic acid $(1 \%)$ and coated with sodium alginate $(1 \%)$. The cubes were packed in trays with cover of polyethylene terephtalate (PET) and stored at $5 \pm 1^{\circ} \mathrm{C}$ and $73 \pm 5 \% \mathrm{HR}$, during 12 days. The cubes were evaluated on their respiratory rate, ethylene production, loss of fresh mass, coloration, texture and humidity content. During the period of storage, independent of the treatment, a reduction of the respiratory rate occurred; ethylene production was not detected in fruits. Chemical treatments had no influence on loss of fresh mass, texture and humidity content; however the film of sodium alginate resulted in darker coloration of melon pulp due to the film solution color.
\end{abstract}

Keywords: Cucumis melo L., minimally processed, respiration, physical parameters.

(Recebido para publicação em 19 de outubro de 2007; aceito em 31 de outubro de 2008) (Received in October 19, 2007; accepted in October 31, 2008)

$\mathrm{O}$ consumo de produtos minimamente processados tem aumentado em todo o mundo. Nos Estados Unidos, a comercialização deste tipo de produto é responsável pelo preparo de cerca de $10 \%$ do volume comercializado de frutas e hortaliças frescas e deverá aumentar para cerca de $20 \%$ nos próximos 10 anos. No Brasil, o consumo deste tipo de produto ainda é pequeno, porém temse observado um rápido crescimento do setor nos grandes e médios centros urbanos, com tendência de expansão (Durigan, 2004).

Apesar do aumento da demanda mundial por vegetais frescos minimamente processados, uma maior expansão neste segmento, tanto para o mercado interno quanto para o externo, tem sido dificultada dada à curta vida útil dos mesmos (Gomes et al., 2005).

A redução da vida útil deste tipo de produto se deve, principalmente, às mudanças fisiológicas indesejáveis, ocasionadas pelas operações envolvidas no processamento, que induzem a perda da integridade celular da superfície cortada, a ocorrência de reações de escurecimento e a formação de metabólitos secundários indesejáveis, além de promover a descoloração, perda da textura e de causar prejuízos ao sabor e ao aroma (Lima, 2000).

Dentre todas as possíveis modificações indesejáveis que este conjunto de processos pode acarretar, o escurecimento oxidativo e a perda acentuada de água é um dos fatores limitantes na conservação de produtos minimamente processados, constituindo uma das principais causas de perda da qualidade visual. Logo, tem-se buscado a utilização de métodos que controlem ou inibam o desencadeamento desses processos para a obtenção de um produto semelhante ao fresco, com vida útil prolongada e de boa qualidade (Lima, 2005).

Procurando controlar estes problemas, tem-se testado o emprego de aditivos químicos como ácido ascórbico, ácido cítrico, cloreto de cálcio (Carva1ho, 2000), películas comestíveis (Pilon, 2007), a adição de antimicrobianos (Sapers et al., 2001) e o uso do 1-MCP (Yamashita et al., 2006).

O ácido ascórbico é um agente antioxidante natural que reduz o escurecimento dos tecidos causado pela enzima polifenoloxidase, formando uma barreira que impede a difusão do oxigênio para o interior do produto, reduzindo as quinonas geradas, antes que sejam formados pigmentos escuros. Entretanto, o ácido é consumido no processo, conferindo uma proteção de caráter temporário contra a descoloração e o escurecimento. Além disso, evita perdas de aroma e sabor, bem como as mudanças na textura e a redução da qualidade nutricional (Chitarra, 2000).

A eficiência do cloreto de cálcio tem sido comprovada por diversos estudos, realizados com produtos minimamente 
processados, relacionados à manutenção da estrutura da parede celular. Groppo (2007) verificou em laranjas 'Pêra' minimamente processadas, tratadas com cloreto de cálcio $1 \%$, uma vida útil de 12 dias, comprovando os efeitos desejáveis da aplicação deste sal no retardamento da maturação, senescência e na manutenção da firmeza.

Além disso, o uso de películas de baixa permeabilidade a gases, como as de polissacarídeos, a exemplo das de alginato de sódio, reduzem as taxas de escurecimento enzimático (Chitarra \& Chitarra, 2005). De fato, alguns autores obtiveram redução nas taxas de escurecimento enzimático em frutas, como resultado da adição de coberturas à base de polissacarídeos (Zhang \& Quantick, 1997; Jiang \& Li, 2001). Além da redução das taxas de escurecimento enzimático, outros efeitos importantes são obtidos na aparência de frutas processadas. $\mathrm{O}$ brilho e melhor integridade estrutural, conferidos pelas películas comestíveis, tornam os produtos mais atraentes para o consumidor (Oliveira et al., 2007).

Este trabalho teve por objetivo avaliar a eficiência do uso de cloreto de cálcio (1\%), ácido ascórbico (1\%) e de película à base de alginato de sódio, na atividade respiratória e no impacto sobre os parâmetros físicos de melões 'Amarelo' minimamente processados.

\section{MATERIAL E MÉTODOS}

Melões 'Amarelo' obtidos junto aos produtores da região de Mossoró (RN), foram colhidos de acordo com o padrão de maturação utilizado pelos produtores, acondicionados em caixa de papelão e transportados para a Companhia de Entrepostos e Armazéns Gerais de São Paulo (CEAGESP) em caminhão com carroceria coberta com lona. Da CEAGESP os frutos foram encaminhados à Planta de Processamento de Frutas e Hortaliças, do Departamento de Agroindústria, Alimentos e Nutrição da USP-ESALQ, onde foram selecionados quanto ao grau de maturação e ausência de danos mecânicos ou podridões, lavados com detergente e em água corrente, para a retirada da sujeira grosseira. Em seguida, os melões sofreram uma desinfecção inicial com imersão em solução contendo 200 ppm de cloro ativo. Após a etapa de desinfecção, os melões foram mantidos sob refrigeração a $10 \pm 1^{\circ} \mathrm{C}$, por 12 horas, até o processamento.

$\mathrm{O}$ processamento foi realizado em ambiente a $15^{\circ} \mathrm{C}$, utilizando-se roupas apropriadas (luvas, máscaras, toucas e aventais descartáveis) como parte das condições mínimas de assepsia. A primeira etapa do processamento consistiu em corte ao meio, utilizando-se faca de aço inoxidável afiada; remoção das sementes (com auxílio de colher). Em seguida, cada metade foi cortada em 4 fatias e a casca eliminada. As fatias foram divididas em pedaços menores com aproximadamente $3 \mathrm{~cm}$ de aresta e estes foram imersos em solução de dicloroisocianurato de sódio dihidratado a 100 ppm por 3 segundos, com o objetivo de reduzir os riscos de contaminação. Os pedaços de melões foram drenados por aproximadamente 3 minutos em escorredor doméstico, devidamente higienizado e divididos em quatro lotes: $\mathrm{L} 1=$ testemunha; $\mathrm{L} 2=$ imersos em solução de cloreto de cálcio a $1 \%$ por 3 minutos e drenados por 3 minutos; L3= imersos em solução de ácido ascórbico a $1 \%$ por 3 minutos e drenados por 3 minutos; $\mathrm{L} 4=$ revestidos com película à base de alginato de sódio. Este tratamento constou primeiramente na imersão dos cubos em solução de cloreto de cálcio a $0,6 \%$, por um minuto para promover a geleificação do alginato de sódio a $1 \%$, o qual foi aplicado na seqüência por imersão durante 2 minutos. A solubilização do alginato de sódio em água mineral foi conseguida pelo aquecimento da suspensão até $70^{\circ} \mathrm{C}$ e posterior resfriamento até $15^{\circ} \mathrm{C}$. Os melões assim tratados foram deixados por 10 minutos em ambiente refrigerado a $15^{\circ} \mathrm{C}$ para a secagem da película. Os cubos foram pesados (250 g) e acondicionados em bandeja Galvanniâ G-92 de tereftalato de polietileno (PET) munida de tampa, com $700 \mathrm{~mL}$ de capacidade.

As embalagens foram armazenadas a $5 \pm 1{ }^{\circ} \mathrm{C}$ e $73 \pm 5 \%$ UR. O período de armazenamento foi de 12 dias, sendo que as avaliações fisiológicas foram realizadas em dias alternados e as avaliações físicas foram realizadas no $1^{\circ}, 3^{\circ}$, $5^{\circ}, 8^{\circ}, 10^{\circ}$ e $12^{\circ}$ dia de armazenamento. Foram avaliados: Taxa respiratória $250 \mathrm{~g}$ de cubos de melão foram colocados em frascos de vidro herméticos com capacidade de $600 \mathrm{~mL}$. Os frascos foram fechados hermeticamente (1h a $5^{\circ} \mathrm{C}$ ), com tampas metálicas contendo um septo de silicone, por onde foram coletadas alíquotas de $1 \mathrm{~mL}$, com auxílio de seringa de vidro. As amostras coletadas foram injetadas em cromatógrafo a gás (Thermoffinigan Trace 2000/GC), dotado de detector de ionização de chama, de coluna Porapack $\mathrm{N}$, de $2 \mathrm{~m}$ de comprimento. As temperaturas mantidas no aparelho foram $100^{\circ} \mathrm{C}$ na coluna, $100^{\circ} \mathrm{C}$ no injetor, $250^{\circ} \mathrm{C}$ no detector e $350^{\circ} \mathrm{C}$ no metanador, para medição de $\mathrm{CO}_{2}$; os resultados foram expressos em $\mu \mathrm{LCO}_{2} \mathrm{~kg}^{-1} \mathrm{~h}^{-1}$; Produção de etileno foi utilizado o mesmo procedimento da análise da taxa respiratória, modificando-se a temperatura do detector para $100^{\circ} \mathrm{C}$. Os frascos permaneceram fechados durante 2 horas. Os resultados foram expressos em $\mathrm{mLC}_{2} \mathrm{H}_{4} \mathrm{~kg}^{-1} \mathrm{~h}^{-1}$; Perda de massa - através da pesagem direta; Cor - determinada em colorímetro Minolta CR 400/410, onde foram determinados os valores de luminosidade (L), $\mathrm{a}^{*} \mathrm{e} \mathrm{b}^{*}$. Esses resultados permitiram calcular o ângulo Hue (cor) e a saturação (Chroma) desta cor, conforme recomendado por Minolta (1994); Textura - determinada com o auxílio de texturômetro "Texture Test System", modelo TP-1 acoplado a um registrador automático de variação de força, operando em célula padrão de compressão de cisalhamento CS-1, com 10 lâminas de $1 / 8$ polegadas de espessura e ângulo de $90^{\circ}$. As amostras foram previamente pesadas e colocadas na célula teste de cisalhamento e compressão, de tal forma que as lâminas das células tivessem ação paralela às amostras. Foi utilizado sensor em 300 lbf (libras-força) e velocidade de descida do pistão de $20 \mathrm{~cm}$ $\min ^{-1}$. Foram feitas medições em dois pedaços de cada embalagem, sendo os resultados expressos em Newton $(\mathrm{N})$; Umidade - determinada em balança determinadora de umidade Tecnal modelo B-Top-Ray, por radiação infravermelha, a qual permitiu expressar os resultados em porcentagem (\%). 


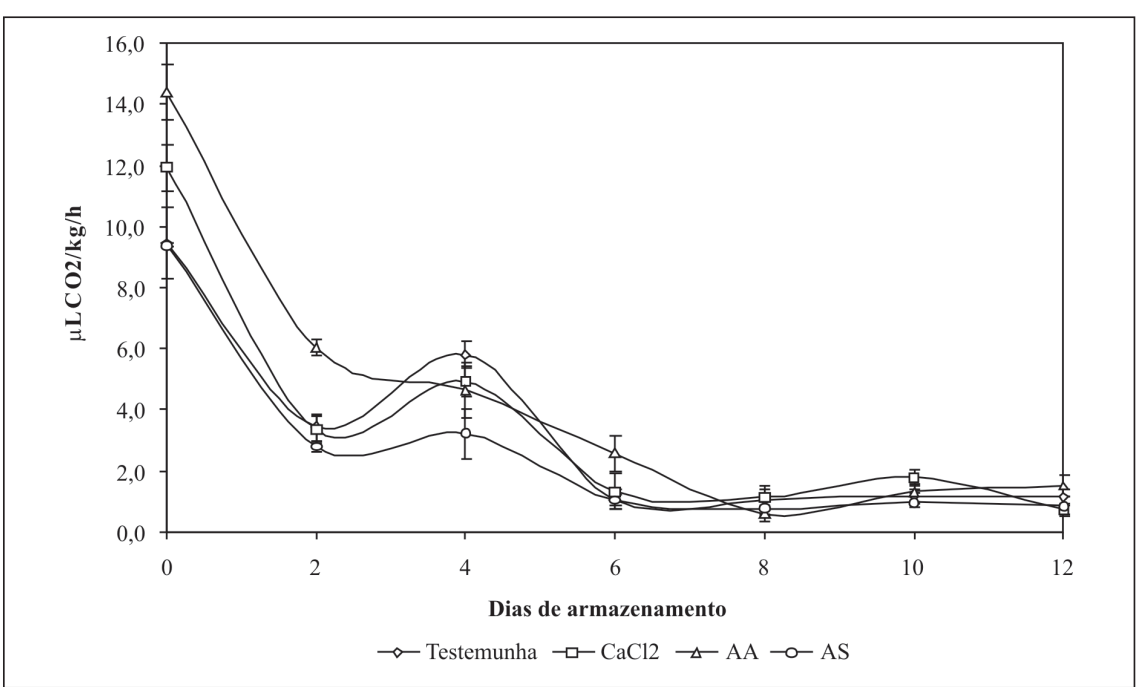

Figura 1. Taxa respiratória de melão 'Amarelo' minimamente processado armazenado a $5^{\circ} \mathrm{C}$, em função dos tratamentos aplicados $\left(\mathrm{CaCl}_{2}=\right.$ cloreto de cálcio; $\mathrm{AA}=$ ácido ascórbico; $\mathrm{AS}=$ alginato de sódio $)\left(\mathrm{CaCl}_{2}=\right.$ calcium chloride; $\mathrm{AA}=$ ascorbic acid; $\mathrm{AS}=$ sodium alginate $)$. (respiratory tax of fresh-cut melon storage at $5^{\circ} \mathrm{C}$, in function of treatments). Piracicaba, USP, 2007.

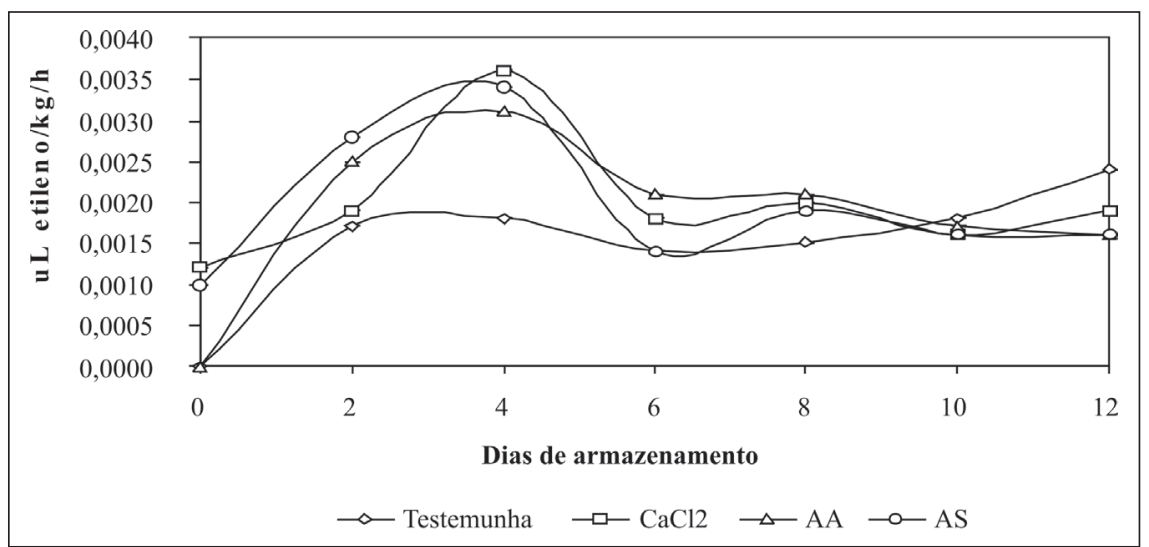

Figura 2. Produção de etileno de melão ‘Amarelo’ minimamente processado armazenado a $5^{\circ} \mathrm{C}$, em função dos tratamentos aplicados $\left(\mathrm{CaCl}_{2}=\right.$ cloreto de cálcio; $\mathrm{AA}=$ ácido ascórbico; $\mathrm{AS}=$ alginato de sódio) $\left(\mathrm{CaCl}_{2}=\right.$ calcium chloride; $\mathrm{AA}=$ ascorbic acid; $\mathrm{AS}=$ sodium alginate). (ethylene production of fresh-cut melon at $5^{\circ} \mathrm{C}$, in function of treatments). Piracicaba, USP, 2007.

O delineamento experimental utilizado foi inteiramente casualizado com esquema fatorial $4 \times 6$ (4 tratamentos e 6 épocas de amostragem) para as análises físicas, $4 \times 7$ (4 tratamentos e 7 épocas de amostragem), para as análises fisiológicas e 3 repetições, tendo como unidade experimental uma embalagem do produto.

Os resultados das análises fisiológicas foram submetidos à análise do erro padrão; enquanto que os das análises físicas foram submetidos à análise de variância pelo Teste $\mathrm{F}$ e a comparação das médias pelo Teste de Tukey (5\%), de acordo com o proposto por Gomes (2002). te. Esse estresse provoca descompartimentação celular e, com isto, os substratos do metabolismo respiratório entram em contato com os complexos enzimáticos, resultado num aumento da atividade respiratória (Purvis, 1997).

O tratamento com ácido ascórbico apresentou a maior taxa respiratória até o $2^{\circ}$ dia de armazenamento, assumindo em seguida valores semelhantes àqueles verificados nos demais tratamentos, indicando que o ácido foi sendo consumido ao longo do tempo, por ser utilizado como substrato para a respiração do vegetal. A aplicação de solução de cloreto de cálcio e de película à base de alginato de sódio não colaborou para a redução da atividade respiratória, pois os melões que receberam tais tratamentos apresentaram valores semelhantes à testemunha nos primeiros dois dias de armazenamento e não diferiram entre si até o final do período experimental. Andrade (2006) e Fontes (2005) observaram que o uso do cloreto de cálcio (1\%) em mamões minimamente processados e de alginato de sódio em maçãs minimamente processadas, respectivamente, mostrou-se eficaz na redução da atividade respiratória, diferindo dos resultados encontrados neste trabalho.

Em todos os tratamentos e durante o período de armazenamento foi detectada produção de etileno (Figura 2), porém em níveis muito baixos, inferiores a $0,1 \mathrm{~mL} \mathrm{C}_{2} \mathrm{H}_{4} \cdot \mathrm{kg}^{-1} \mathrm{~h}^{-1}$, sem interesse do ponto de vista de fisiologia e tecnologia pós-colheita, uma vez que este regulador de amadurecimento começa a ser fisiologicamente ativo a partir do nível citado (Reid, 1992). Os dados verificados neste trabalho, estão de acordo com os relatados por Almeida et al. (2001) que também não detectaram produção de etileno em melão 'Amarelo'. Segundo Saltveit (2000), apesar da biossíntese do etileno ser ativada pela ocorrência de danos físicos, nem todos os tecidos vegetais, como o observado em melão 'Amarelo', respondem a este estresse com aumentos significativos na produção deste hormônio, ou esta é tão baixa que não é capaz de ser detectada.

Ocorreu uma gradativa perda de massa ao longo do período de armazenamento (Tabela 1). Este aumen- 
to pode ser atribuído à perda de umidade e de material de reserva pela transpiração e respiração, respectivamente. Entretanto, ao longo dos 12 dias de armazenamento esta perda foi pequena, podendo ser devido à proteção oferecida ao produto pela embalagem, como proposto por Sarantópoulos (1997) e Durigan (2000). Estes resultados são importantes, haja vista que a perda de massa do melão pode representar sério prejuízo econômico, pois normalmente o fruto é vendido por unidade de massa (Peroni, 2002).

Em relação ao efeito dos tratamentos (Tabela 1), os cubos tratados com cloreto de cálcio (1\%) apresentaram a maior perda de massa, indicando que a aplicação do sal clorado foi pouco eficaz na redução da perda de peso. Peroni (2002), estudando o efeito de diferentes concentrações de $\mathrm{CaCl}_{2}$ em melão 'Amarelo' minimamente processado, verificou uma perda média de $0,11 \%$, valor inferior ao encontrado neste trabalho. Os melões testemunha, os tratados com ácido ascórbico e os revestidos com película não apresentaram diferenças quanto à perda de massa. Estes resultados vão ao encontro do observado por Lima (2005) em melões 'Orange Flesh' minimamente processados, tratados com ácido ascórbico, que constatou comportamento semelhante entre a testemunha e os frutos imersos em ácido. A película de alginato de sódio não apresentou efeito significativo na redução da perda de massa. Em relação aos tratamentos, os resultados encontrados ficaram abaixo dos valores críticos de perda de massa indicados por Finger \& Vieira (1997), que afirmam que a perda de massa máxima, sem aparecimento de murchamento ou enrugamento da superfície oscila entre 5 e $10 \%$ e que a perda de massa aceitável para os produtos hortícolas varia de em função da espécie e do nível de exigência dos consumidores.

A coloração do produto é um dos principais parâmetros para a caracterização da qualidade, pois os consumidores mantêm uma relação positiva entre esses dois fatores (Chitarra \& Alves, 2001). Os valores de luminosidade (L), obtidos nesse trabalho, de maneira geral, decresceram durante o armazenamento, indicando que houve

Tabela 1. Perda de massa fresca, Luminosidade (L), cromaticidade (C) e umidade em melões 'Amarelo' minimamente processados, em função dos tratamentos e do tempo de armazenamento (fresh mass lose, luminosity (L), cromaticity (C) and humidity in fresh-cut melons, in function of treatments and storage). Piracicaba, USP, 2007.

\begin{tabular}{lcccc}
\hline Variável & $\begin{array}{c}\text { Perda } \\
\text { acumulada (\%) }\end{array}$ & $\mathbf{L}$ & $\mathbf{C}$ & Umidade (\%) \\
\hline Tratamento & $0,15 \mathrm{~b}$ & $66,98 \mathrm{a}$ & $10,48 \mathrm{a}$ & $93,25 \mathrm{a}$ \\
$\mathrm{T}$ & $0,20 \mathrm{a}$ & $66,90 \mathrm{a}$ & $9,96 \mathrm{a}$ & $93,15 \mathrm{a}$ \\
$\mathrm{CaCl}_{2}$ & $0,16 \mathrm{~b}$ & $63,35 \mathrm{~b}$ & $10,76 \mathrm{a}$ & $92,97 \mathrm{a}$ \\
$\mathrm{AA}$ & $0,16 \mathrm{~b}$ & $57,64 \mathrm{c}$ & $8,72 \mathrm{a}$ & $93,38 \mathrm{a}$ \\
$\mathrm{AS}$ & & & & \\
\hline Armazenamento (dias) & $0,00 \mathrm{~d}$ & $65,67 \mathrm{a}$ & $10,66 \mathrm{a}$ & $91,62 \mathrm{~b}$ \\
1 & $0,06 \mathrm{c}$ & $63,38 \mathrm{ab}$ & $10,36 \mathrm{a}$ & $93,32 \mathrm{a}$ \\
3 & $0,10 \mathrm{c}$ & $64,19 \mathrm{a}$ & $11,63 \mathrm{a}$ & $93,27 \mathrm{a}$ \\
5 & $0,22 \mathrm{~b}$ & $64,91 \mathrm{a}$ & $9,08 \mathrm{a}$ & $93,81 \mathrm{a}$ \\
8 & $0,28 \mathrm{~b}$ & $63,68 \mathrm{ab}$ & $9,17 \mathrm{a}$ & $93,50 \mathrm{a}$ \\
10 & $0,34 \mathrm{a}$ & $60,48 \mathrm{~b}$ & $8,90 \mathrm{a}$ & $93,52 \mathrm{a}$ \\
12 & 28,30 & 6,31 & 32,88 & 0,93 \\
\hline CV (\%) & & &
\end{tabular}

Médias seguidas de mesma letra nas colunas não diferem entre si, pelo teste de Tukey, a 5\% de probabilidade) (Average values followed from the same letter in the column did not differ through the Tukey test, $5 \%$ probability); $\mathrm{T}=$ testemunha; $\mathrm{CaCl}_{2}=$ cloreto de cálcio; $\mathrm{AA}=$ ácido ascórbico; $\mathrm{AS}=$ alginato de sódio $\left(\mathrm{T}=\right.$ control $; \mathrm{CaCl}_{2}=$ calcium chloride; $\mathrm{AA}=$ ascorbic acid; AS = sodium alginate).

Tabela 2. Valores médios de ângulo de cor $\left(h^{\circ}\right)$ e de textura de melões 'Amarelo' minimamente processados, em função dos tratamentos e do tempo de armazenamento (average values of color angle and texture of fresh-cut melons, depending on treatments and storage). Piracicaba, USP, 2007.

\begin{tabular}{|c|c|c|c|c|c|c|}
\hline \multicolumn{7}{|c|}{ Ângulo de cor $\left(h^{\circ}\right)$} \\
\hline \multirow{2}{*}{ Tratamento } & \multicolumn{6}{|c|}{ Tempo de armazenamento (dias) } \\
\hline & 1 & 3 & 5 & 8 & 10 & 12 \\
\hline $\bar{T}$ & $105,91 \mathrm{aAB}$ & $109,18 \mathrm{aA}$ & 108,96 aA & $107,66 \mathrm{aAB}$ & $106,82 \mathrm{aAB}$ & $103,85 \mathrm{aB}$ \\
\hline $\mathrm{CaCl}_{2}$ & 105,49 aA & $107,04 \mathrm{aA}$ & $108,36 \mathrm{aA}$ & $106,36 \mathrm{abA}$ & $104,30 \mathrm{aA}$ & $106,81 \mathrm{aA}$ \\
\hline AA & $108,23 \mathrm{aA}$ & $106,47 \mathrm{aA}$ & $108,58 \mathrm{aA}$ & $104,81 \mathrm{abA}$ & $104,95 \mathrm{aA}$ & $107,74 \mathrm{aA}$ \\
\hline AS & $106,02 \mathrm{aA}$ & $105,34 \mathrm{aA}$ & $106,02 \mathrm{aA}$ & $103,17 \mathrm{bA}$ & $106,89 \mathrm{aA}$ & $104,31 \mathrm{aA}$ \\
\hline \multicolumn{7}{|c|}{ Textura (N) } \\
\hline \multirow{2}{*}{ Tratamento } & \multicolumn{6}{|c|}{ Tempo de armazenamento (dias) } \\
\hline & 1 & 3 & 5 & 8 & 10 & 12 \\
\hline $\bar{T}$ & $0,43 \mathrm{aAB}$ & $0,39 \mathrm{cB}$ & $0,62 \mathrm{aA}$ & $0,56 a b A B$ & $0,41 \mathrm{bB}$ & $0,41 \mathrm{aB}$ \\
\hline $\mathrm{CaCl}_{2}$ & $0,59 \mathrm{aB}$ & $0,74 \mathrm{aB}$ & $0,58 \mathrm{aB}$ & $0,59 a b B$ & $1,01 \mathrm{aA}$ & $0,57 \mathrm{aA}$ \\
\hline AA & $0,45 \mathrm{aA}$ & $0,62 a b A$ & $0,63 a A$ & $0,47 \mathrm{bA}$ & $0,46 \mathrm{bA}$ & $0,48 \mathrm{aA}$ \\
\hline AS & $0,45 \mathrm{aB}$ & $0,56 \mathrm{bB}$ & $0,56 \mathrm{aAB}$ & $0,72 \mathrm{aA}$ & $0,53 \mathrm{bAB}$ & $0,50 \mathrm{aB}$ \\
\hline
\end{tabular}

Médias seguidas da mesma letra minúscula nas colunas e maiúscula nas linhas não diferem entre si, pelo teste de Tukey a 5\% de probabilidade (means followed by the same small letter in the columns and capital letter in the rows did not differ from each other through the Tukey test, $5 \%) . \mathrm{T}=$ testemunha; $\mathrm{CaCl}_{2}=$ cloreto de cálcio; $\mathrm{AA}=$ ácido ascórbico; $\mathrm{AS}=$ alginato de sódio ( $\mathrm{T}=$ control $; \mathrm{CaCl}_{2}=$ calcium chloride; $\mathrm{AA}=$ ascorbic acid; $\mathrm{AS}=$ sodium alginate $)$.

escurecimento da polpa do melão com o avanço dos dias (Tabela 1). Arruda (2002) e Pinto (2002) também observaram diminuição nos valores de luminosidade em melões rendilhados e em melões ‘Orange Flesh' minimamente processados, respectivamente.
Os melões tratados com alginato de sódio apresentaram o menor valor médio de luminosidade, o que pode ser atribuído à coloração da solução de alginato de sódio, que é levemente marrom, fato também constatado por Fontes (2005) em maçãs minimamente processadas 
revestidas com este tipo de película. Os melões testemunha e os tratados com cloreto de cálcio (1\%) mostraram-se mais claros e com valores de L semelhantes, indicando que o uso deste sal não influenciou significativamente na taxa de escurecimento dos frutos. Peroni (2002), estudando o efeito do $\mathrm{CaCl}_{2} \mathrm{em}$ melões, constatou diminuição no valor de L ao longo do período de armazenamento e no último dia $\left(10^{\circ} \mathrm{dia}\right)$ verificou translucidez no produto, sinalizando senescência.

Em relação à cromaticidade, os tratamentos químicos e o período de armazenamento não influenciaram na pigmentação amarelada da polpa dos melões minimamente processados (Tabela 1).

Houve interação significativa entre os tratamentos e o período de armazenamento com relação ao ângulo de cor (Tabela 2). O ângulo hue ou de cor se manteve praticamente inalterado ao longo do período de armazenamento em todos os tratamentos, exceto em relação à testemunha, a qual tendeu a se tornar mais amarelada, passando de $105,19^{\circ}$ para $103,85^{\circ}$, indicando que estes melões estavam em estádio mais avançado de maturação. Em relação aos tratamentos, os melões apenas diferiram entre si quanto ao ângulo de cor no $8^{\circ}$ dia de armazenamento, sendo que os frutos tratados com alginato de sódio apresentaram o menor valor médio para o ângulo de cor, denotando coloração mais amarelada. Os resultados são concordantes com os obtidos por Fontes (2005), que também constatou menores valores do ângulo de cor em maçãs minimamente processadas revestidas com película comestível.

Com base nos resultados acima citados, pode se afirmar que os tratamentos químicos não modificaram a coloração natural dos melões minimamente processados, ou seja, colaboraram para a preservação da coloração. Este é um dado importante, uma vez que os parâmetros que definem a coloração também podem ser indicativos da perda de qualidade, pois quando o produto muda suas características originais, escurecendo e/ou adquirindo outra tonalidade, entende-se que sua aparência característica é perdida e sua aceitação é menor (Chitarra, 1994).
Os teores de umidade dos melões minimamente processados não variaram significativamente entre os tratamentos, não influenciando na umidade das amostras (Tabela 1). Os melões minimamente processados não apresentaram perdas significativas de umidade com o decorrer do tempo. Estes resultados refletem o efeito conjugado da pequena perda de massa (transpiração) e da atividade metabólica reduzida observada ao longo do período de armazenamento.

A textura foi significativamente afetada pelos tratamentos e pelo período de armazenamento (Tabela 2). Embora tenha havido oscilações ao longo dos dias de avaliação, no $12^{\circ}$ dia, em todos os tratamentos os melões apresentaram valores de textura semelhantes aos do primeiro dia, não havendo amaciamento da polpa, evento comumente observado em frutas e hortaliças e que tem sido atribuído à modificação na composição da parede celular pela ação de enzimas (Chitarra, 2000).

Para os tratamentos, houve diferenças significativas somente no $3^{\circ}, 8^{\circ} \mathrm{e}$ $10^{\circ}$ dias, tendo a testemunha apresentado os menores valores, os tratados com ácido ascórbico textura mais macia e os tratados com cloreto de cálcio textura mais rígida. Contudo, pode-se dizer que os tratamentos químicos não contribuíram para maior efeito na textura dos melões, o que pode ser resultado das perdas de massa terem sido mínimas.

Pode-se concluir que todos os tratamentos químicos testados demonstraram tendência de decréscimo na atividade respiratória durante o armazenamento refrigerado, indicando que esta não contribui para a redução da vida útil dos melões 'Amarelo' minimamente processados e que os mesmos, não influenciaram na perda de massa, textura e umidade, porém o uso de película à base de alginato de sódio resultou em melões de coloração mais escura da polpa, em decorrência da cor da solução filmogênica.

\section{AGRADECIMENTOS}

Ao Cnpq pela bolsa de mestrado concedida à primeira autora.

\section{REFERÊNCIAS}

ALMEIDA AS; FILGUEIRAS HAC; MENEZES JB; ALVES RE; PEREIRA MEC; ALMEIDA AV. 2001. Atividade Respiratória e produção de etileno em diferentes híbridos de melão cultivados no pólo agrícola Mossoró-Açú. In: CONGRESSO BRASILEIRO DE OLERICULTURA, 41. Resumos... Brasília: SOB (CD-ROM).

ANDRADE SRR. 2006. Processamento mínimo de mamão (Carica papaya L.): efeitos de aditivos químicos e atmosfera modificada na qualidade do produto. Piracicaba: USPESALQ. 178p (Tese mestrado).

ARRUDA MC. 2002. Processamento mínimo de melão rendilhado: tipo de corte, temperatura de armazenamento e atmosfera modificada. Piracicaba: USP-ESALQ. 71p (Tese mestrado).

CARVAlHO AV. 2000. Avaliação de kiwi cv. Hayward minimamente processado. Lavras: UFLA. 86p (Tese doutorado).

CHITARRA AB; ALVES RE. 2001. Tecnologia de pós-colheita para frutas tropicais. Fortaleza: FRUTAL-SINDIFRUTA.

CHITARRA MIF. 1994. Colheita e qualidade póscolheita de frutos. Informe Agropecuário 17: 8-18.

CHITARRA MIF. 2000. Processamento mínimo de frutos e hortaliças. Lavras: UFLA-FAEPE. $113 \mathrm{p}$.

CHITARRA MIF; CHITARRA AB. 2005. Póscolheita de frutas e hortaliças: fisiologia e manuseio. Lavras: UFLA. 785p.

DURIGAN JF. 2000. Processamento mínimo de frutas. In: ENCONTRO NACIONAL SOBRE PROCESSAMENTO MÍNIMO DE FRUTAS E HORTALIÇAS, 2. Palestras... Viçosa: UFV. p. $86-88$

DURIGAN JF. 2004. Processamento de frutas e hortaliças. Fortaleza: Instituto Frutal. 69p.

FINGER FL; VIEIRA G. 1997. Controle da perda pós-colheita de água em produtos minimamente processados. Viçosa: UFV. 29p.

FONTES LCB. 2005. Uso de solução conservadora e de películas comestíveis em maçãs da cultivar Royal Gala minimamente processadas: efeito na fisiologia e na conservação. Piracicaba: USP-ESALQ. 118p (Tese mestrado).

GOMES CAO; ALVARENGA ALB; JUINIOR MF; CENCI SA. 2005. Hortaliças Minimamente Processadas. Brasília: Embrapa Informação Tecnológica. 34p.

GOMES FP. 2002. Estatística aplicada a experimentos agronômicos e florestais. Piracicaba: FEALQ. 309p.

GROPPO VD. 2007. Laranja 'Pêra' (Citrus sinensis L. Osbeck) minimamente processada: efeito do cloreto de cálcio e película de alginato de sódio na fisiologia e conservação. Piracicaba: USP - ESALQ. 98p (Tese mestrado).

JIANG Y; LI Y. 2001. Effects of chitosan coating on postharvest life and quality of longan fruit. Food Chemistry 73: 139-143. 
LIMA LC. 2000. Processamento mínimo de kiwi e mamão. In: ENCONTRO NACIONAL SOBRE PROCESSAMENTO DE FRUTAS E HORTALIÇAS, 2. Palestras... Viçosa: UFV. p. 95-109.

LIMA LC. 2005. Qualidade do melão 'Orange Flesh' minimamente processado e submetido a diferentes métodos de conservação. Botucatu: UNESP-FCA. 130p (Tese doutorado).

MINOLTA. 1994. Precise color communication: color control from feeling to instrumentation. Ramsey: Minolta Corporation Instrument Systems Division. 49p.

OLIVEIRA CS; GRDEN L; RIBEIRO COM. 2007. Utilização de filmes comestíveis em alimentos. Série em Ciência e Tecnologia de Alimentos: Desenvolvimentos em Tecnologia de Alimentos 1: 52-57.

PERONI KMC. 2002. Influência do cloreto de cálcio sobre a vida de prateleira de melão 'amarelo' minimamente processado. Lavras: UFLA. 86p (Tese mestrado).
PILON L. 2007. Conservação de abacaxi minimamente processado utilizando como coadjuvantes cloreto de cálcio, película comestivel e radiação gama. Piracicaba: USPCENA. 120p (Tese doutorado).

PINTO SAA. 2002. Processamento mínimo de melão tipo Orange Flesh e de melancia 'Crimson Sweet'. Jaboticabal: UNESP-FCAV. 120p (Tese mestrado).

PURVIS AC. 1997. The role of adaptive enzymes in carbohydrates oxidation by stressed and senescing plant tissues. HortScience 32: 11651168.

REID MS. 1992. Ethylene in postharvest technology. In: KADER, AA. (ed). Postharvest technology of horticultural crops. Oakland: University of California. p. 97-108.

SALTVEIT ME. 2000. Fresh-cut product biology. Fresh-cut products: maintaining quality and safety. 12 a 14 de setembro. University of California: Davis, California.
SAPERS GM; MILLER RL; PILIZOTA V; MATTRAZZO AM. 2001. Antimicrobial treatments for minimally processed cantaloupe melon. Journal of Food Science 66: 345-349.

SARANTÓPOULOS CIGL. 1997. Embalagens para vegetais minimamente processados - fresh cut. Boletim Informativo do Centro de Tecnologia de Embalagem 9: 8-11.

YAMASHITA F; MATIAS AN; GROSSMANN MVE; ROBERTO SR; BENASSI MT. 2006. Embalagem ativa para brócolis minimamente processado utilizando 1-metilciclopropeno em sachê biodegradável. Semina: Ciências Agrárias 27: 581-586.

ZHANG DL; QUANTICK PC. 1997. Effect of chitosan coating on enzymatic browning and decay during post-harvest storage of litchi (Litchi chinensis Sonn.) fruit. Postharvest Biology and Technology 12: 195-202. 